\title{
LA NECESARIA REFORMA DEL SISTEMA PREVISIONAL EN EL PERÚ
}

\section{THE NECESSARY REFORM OF THE PENSION SYSTEM IN PERU}

\section{DANIEL DE LA VEGA ZAVALA}

Abogado por la Facultad de Derecho de la Pontificia Universidad Católica del Perú. Asociado Senior del Estudio Rodrigo, Elías \& Medrano Abogados.

e-Revista Internacional de la Protección Social, ISNN 2445-3269. 2018, Vol. III, Nº 1 


\title{
RESUMEN
}

En Perú coexisten dos regímenes de pensiones: un sistema público, el Sistema Nacional de Pensiones (SNP), y un sistema privado, el Sistema Privado de Pensiones (SPP). El primero es de financiación mixta mientras que el segundo es un régimen de capitalización individual.

Con el objeto de plantear reformas económicas para financiar la cobertura universal de aseguramiento de salud y protección previsional sin afectar la sostenibilidad fiscal ni generar informalidad en el mercado de trabajo se creó en 2017 el Grupo de Trabajo "Comisión de Protección Social", dependiente del Ministerio de Economía y Finanzas. En su primer informe propuso desarrollar un sistema de pensiones de afiliación automática, integrado, eficiente e independiente de la condición laboral, de modo que ningún peruano se quede sin una pensión básica.

PALABRAS CLAVE: Seguridad Social, pensiones, Perú, reformas.

\begin{abstract}
In Peru, two pension systems coexist: a public system, the National Pension System (SNP) and a private system, the Private Pension System (SPP). The first one is mixed financing while the second one is an individual capitalization regime.

In order to propose economic reforms to finance universal coverage of health insurance and pension protection without affecting fiscal sustainability or generating informality in the labor market, the Working Group "Social Protection Commission" was created in 2017, it dependent of the Ministry of Economy and Finance. In its first report, it proposed to develop a system of pensions with automatic affiliation, integrated, efficient and independent of the working condition, so that no Peruvian would be left without a basic pension.
\end{abstract}

KEYWORDS: Social Security, pensions, Peru, reforms.

e-Revista Internacional de la Protección Social, ISNN 2445-3269. 2018, Vol. III, Nº 1

http://dx.doi.org/10.12795/e-RIPS.2018.i02.07. Páginas: 135-149.

Página 136 
SUMARIO

I. ANTECEDENTES DEL SISTEMA PREVISIONAL EN EL PERÚ

II. EL SISTEMA PREVISIONAL VIGENTE EN EL PERÚ

III. LA NECESIDAD DE LA REFORMA: PROBLEMÁTICA CON EL SISTEMA DE PENSIONES

IV. REFORMA EN CAMINO: SISTEMA DE PENSIONES INTEGRADO

V. REFLEXIÓN FINAL

e-Revista Internacional de la Protección Social, ISNN 2445-3269. 2018, Vol. III, No 1

http://dx.doi.org/10.12795/e-RIPS.2018.i02.07. Páginas: 135-149. Página 137 


\section{ANTECEDENTES DEL SISTEMA PREVISIONAL EN EL PERÚ}

En el Perú, el beneficio de jubilación ha sido regulado por diferentes cuerpos normativos. En la actualidad, coexisten dos regímenes de pensiones: uno público, el Sistema Nacional de Pensiones (SNP) administrado por la ONP y; otro, privado, el Sistema Privado de Pensiones administrado por las AFP.

Fue a inicios del siglo pasado que por primera vez la empresa privada asumió la administración del pago de una prestación previsional ${ }^{1}$, pues mediante la Ley $\mathrm{N}^{\mathrm{o}} 1378$, se estableció la obligación del empleador de asumir la responsabilidad por los accidentes de trabajo que les ocurrieran a sus empleados en el hecho del trabajo o con ocasión del mismo.

En esta etapa, las normas de carácter previsional incluían a todos los trabajadores, obreros o empleados, a cargo de un empleador, sin hacer distinción por la naturaleza del régimen laboral. Sin embargo, la distinción entre obreros y empleados se extendió a la legislación laboral y previsional. De esta manera, en el caso de los obreros, de acuerdo con la Ley $\mathrm{N}^{\mathrm{0}} 8433$, promulgada en 1936, gozaban a su favor de una pensión de vejez a cargo de la Caja Nacional del Seguro Social Obrero.

Por otro lado, los empleados carecían de este beneficio hasta la promulgación de la Ley $\mathrm{N}^{\circ}$ 10624. Dicha norma reguló el derecho al pago de una pensión a cargo del empleador, equivalente a un sueldo íntegro para los empleados con 40 años de servicio ininterrumpidos a las entidades bancarias, comerciales, industriales, agrícolas y mineras, que tuvieran un capital mayor a dos millones de oro.Con el Decreto Ley No 11013 y el Decreto Ley $\mathrm{N}^{\mathrm{o}} 15117$, se redujeron los años de servicio exigidos para acceder a la jubilación, fijando 30 años de servicio para los hombres y 25 años para las mujeres.

Más adelante, con el Decreto Ley $\mathrm{N}^{\mathrm{0}} 17262$, se creó el Fondo de Jubilación de los Empleados Particulares (FEJEP), el cual asumió a los trabajadores que estaban comprendidos en la Ley $\mathrm{N}^{\mathrm{o}} 10624$ que no estuvieran percibiendo pensión de jubilación bajo dicha norma. El FEJEP fue administrado por el Seguro Social del Empleado, y para acceder a una pensión de jubilación se debía acreditar 20 o 25 años de servicio para un mismo empleador.

Años después, esta norma fue derogada mediante el Decreto Ley $\mathrm{N}^{\circ}$ 19990, el cual creó el SNP en sustitución de los sistemas de pensiones de las Cajas de Pensiones de la Caja Nacional de Seguro Social y del Seguro Social del Empleado y del Fondo Especial de Jubilación de Empleados Particulares. Este Régimen beneficia a los trabajadores sujetos al régimen laboral de la actividad privada, a los trabajadores obreros y a los funcionarios y servidores públicos sujetos al régimen de la actividad pública, que no se encuentran incorporados al Decreto Ley Nº 20530.

Por otro lado, el 19 de julio de 1980, con la dación del Decreto Ley N $\mathrm{N}^{\mathrm{0}}$ 23161, se creó el Instituto Peruano de Seguridad Social (IPSS), como una institución autónoma y

\footnotetext{
${ }^{1}$ ABANTO REVILLA, César. (2015) "Regímenes complementarios de jubilación en el Perú ¿una opción paralela?". En: DERECHO PUCP, No 75. Lima.

e-Revista Internacional de la Protección Social, ISNN 2445-3269. 2018, Vol. III, No 1

http://dx.doi.org/10.12795/e-RIPS.2018.i02.07. Páginas: 135-149.

Página 138
} 
descentralizada con autonomía técnica, económica y administrativa, con personería jurídica de derecho público interno, que tenía a su cargo cubrir a los asegurados y sus familiares contra los riesgos de enfermedad, maternidad, invalidez, accidente, vejez y muerte y contra cualquier otra situación factible de ser amparada y señalada por ley.

Tal como señala $\mathrm{NEVES}^{2}$, antes de la reforma del sistema de pensiones, existía en el campo previsional una convivencia parcial entre el sector social y el privado. Precisamente, el IPSS administraba dos sistemas generales y uno especial. Los dos primeros son el Régimen de Prestaciones de Salud (RPS) y el Sistema Nacional de Pensiones (SNP), regulados por el Decreto Ley No 22484 y 19990, respectivamente. El especial, era el Régimen de Accidentes de Trabajo y Enfermedades Profesionales (RATEP), regulado en el Decreto Ley N ${ }^{\circ} 18846$.

Sin embargo, el SNP regulado por la Ley $\mathrm{N}^{\circ} 19990$ al ser un sistema de reparto, los trabajadores activos afiliados aportaban a un fondo comunitario, dicho fondo era el que proveía de recursos a las prestaciones de jubilación, invalidez y sobrevivencia que se otorgaban $^{3}$. Sin embargo, los cambios geográficos, laborales y económicos (el elevado número de trabajadores informales, el desempleo, entre otros factores), y el aumento de la expectativa de la vida terminaron por afectar el funcionamiento de este tipo de regímenes de pensiones ${ }^{4}$.

El desgaste de este sistema, además de la crisis política, condujo a la reforma del Sistema de Pensiones. Así, en noviembre de 1992, a través del Decreto Ley No 25897, se creó el Sistema Privado de Administración de Fondos de Pensiones (SPP), en virtud del cual se instauró un sistema de capitalización individual administrado por las AFP, en el cual, cada afiliado posee una cuenta individual donde se depositan sus cotizaciones.

\section{EL SISTEMA PREVISIONAL VIGENTE EN EL PERÚ}

De acuerdo con el ordenamiento peruano vigente, coexisten dos regímenes de pensiones: un sistema público, el Sistema Nacional de Pensiones (SNP), regulado por el Decreto Ley No 19990; y, un sistema privado, el Sistema Privado de Pensiones (SPP), regulado por el Decreto Supremo No 054-97-EF.

Si bien se ha señalado que ambos regímenes son abiertos y excluyentes, pues cualquier trabador puede optar y afiliarse por uno de ellos ${ }^{5}$, el objetivo transparente de la legislación es provocar la migración de los asegurados del SNP al SPP.

A continuación, precisaremos algunas características generales de ambos sistemas:

\footnotetext{
${ }^{2}$ NEVES MUJICA, JAVIER (1993). "Sistema Nacional de Pensiones y Sistema Privado de Pensiones: Opción Diabólica". En: Themis, No 25. Lima.

${ }^{3}$ ALARCÓN, Guillermo. (1993). Entrevista: "El Nuevo Sistema Privado de Pensiones". En: Temis, No 26. Lima.

${ }^{4}$ MEDIOLA, Alfredo y otros. (2013). Análisis del sistema privado de pensiones: propuesta de reforma y generación de valor. Primera Edición. Lima: Esan Ediciones.

${ }_{5}^{5}$ TOYAMA MIYAGUSUKU, Jorge y ÁNGELES LLERENA, Karen. (2004) "Seguridad Social Peruana: Sistemas y Perspectivas". En Themis, Nº 48 . Lima.

e-Revista Internacional de la Protección Social, ISNN 2445-3269. 2018, Vol. III, Nº 1

http://dx.doi.org/10.12795/e-RIPS.2018.i02.07. Páginas: 135-149.

Página 139
} 
(i) El SNP es un sistema de financiamiento mixto, pues las pensiones de los jubilados en un periodo determinado se financian primordialmente con los aportes que realizan los trabajadores activos en el mismo periodo ${ }^{6}$. En este sentido, los aportes se destinan a un fondo común. Por el contrario, el SPP es un régimen de capitalización individual, en el cual los aportes que realiza cada afiliado se registran en una cuenta individual de capitalización(CIC), la que se incrementa con los sucesivos aportes y la rentabilidad generada por las inversiones del fondo. Es importante considerar que el Estado también participa en el financiamiento de las CIC a través de los bonos de reconocimiento, los cuales se otorgan para reconocer los aportes al SNP; y, de los bonos complementarios, los cuales se usan para financiar pensiones mínimas ${ }^{7}$.

(ii) El SNP es administrado por una entidad estatal, nos referimos a la ONP, quien además se encarga de administrar de los pagos a los pensionistas de otros regímenes administrados por el Estado y los regímenes especiales. Mientras que el SPP es administrado por entidades privadas, denominadas AFP, las cuales son empresas privadas supervisadas por la Superintendencia de Banca y Seguros $(\mathrm{SBS})^{8}$.

Cabe señalar que la legislación desalienta la permanencia en el SNP y favorece abiertamente la afiliación a las AFP. Por nombrar un par de ejemplos, tenemos los incentivos económicos que se otorgaron a los afiliados al SNP que optaron por trasladarse a una AFP (aumentos) y el hecho que si un trabajador no elije, en un plazo de 10 días desde el inicio de su relación laboral, un sistema previsional, el empleador está obligado a afiliarlo al SPP en alguna AFP.

A propósito, cabe anotar que de la población afiliada a un Sistema de Pensión, las AFP son las que cuentan con mayor número de afiliados con 4 millones 482 mil 100 personas $(19,2 \%)$, la ONP tiene 2 millones 518 mil 800 personas $(10,8 \%)$ y otros sistemas de pensión, 277 mil 800 personas $(1,2 \%)^{9}$.

Igualmente, en el periodo 2011-2016, los afiliados a una AFP se han incrementado en 3,6 puntos porcentuales, al pasar de 15,6\% el 2011 a 19,2\% al primer semestre de 2016. En el caso de la ONP en 1,3 puntos porcentuales al pasar de $9,5 \%$ a $10,8 \%$ en el mismo periodo ${ }^{10}$.

(iii) En relación a quienes tiene derecho a afiliarse al SNP, éste sólo comprende a los trabajadores dependientes (con carácter obligatorio) y a trabajadores independientes (de manera facultativa). Por su parte, el SPP permite la afiliación voluntaria de trabajadores dependientes e independientes; y, las personas que no

\footnotetext{
${ }^{6}$ Ibídem.

${ }^{7}$ CASALÍ, Pablo y PENA, Hernán. Los trabajadores independientes y la Seguridad Social en el Perú. (2012). Organización Internacional del Trabajo. Primera Edición: Lima.

${ }^{8}$ A partir del 25 de julio de 2000, la SBS asumió las funciones de la Superintendencia de AFP, de acuerdo a lo dispuesto en la Ley $\mathrm{N}^{\circ} 27238$.

9 INSTITUTO NACIONAL DE ESTADÍSTICA E INFORMÁTIC (INEI) (2016). "Cobertura del Sistema de Pensiones. Síntesis Estadística". Disponible en: https://www.inei.gob.pe/media/MenuRecursivo/boletines/boletin_pensiones.pdf ${ }^{10}$ Ibídem.

e-Revista Internacional de la Protección Social, ISNN 2445-3269. 2018, Vol. III, No 1

http://dx.doi.org/10.12795/e-RIPS.2018.i02.07. Páginas: 135-149. 
tengan la condición de trabajadores dependientes o independientes pueden afiliarse voluntariamente a la AFP que elijan, en calidad de afiliados potestativos ${ }^{11}$.

(iv) El SNP tiene un sistema de beneficios determinados por Ley, de manera que, no existe relación entre el monto de lo aportado y la pensión que se va a recibir. De ahí que algunos consideran que este sistema es injusto e inequitativo para quienes aportaron a lo largo de sus años de servicio, pues al margen del monto aportado, al momento de su jubilación perciben pensiones irrisorias. Enel SPP existe una relación entre lo aportado por el trabajador y el monto que figura en su CCI con la pensión a percibir ${ }^{12}$.

(v) En el SNP para acceder a una pensión de jubilación se debe cumplir, entre otros requisitos, con tener 20 años de aportación y siempre que el trabajador (hombre o mujer) cuente con 65 años de edad. Sin embargo, en el SPP no se exige un mínimo de años de aportación, pues la pensión se determinará en función a los aportes acumulados que hubiera efectuado el trabajador y la rentabilidad obtenida por el fondo administrado por la $\mathrm{AFP}^{13}$.

(vi) La cuantía de la pensión, en el SNP, será equivalente al 50\% de la remuneración de referencia del afiliado, la cual se determina en función del tiempo de aportación. El porcentaje mencionado se irá incrementando por cada año adicional completo de aportación en 4\% hasta alcanzar como límite el $100 \%$ de la remuneración de referencia. La pensión máxima a la fecha es de $\mathrm{S} / 857.36$ Soles (aproximadamente US\$263 Dólares Americanos).

A diferencia de ello, en el SPP, la pensión de jubilación se calcula en base al saldo que arroje la CIC del afiliado al momento que le corresponde la prestación, en función a los siguientes factores: a) el capital acumulado formado por los aportes mensuales, el monto del bono de reconocimiento, si corresponde; $\mathrm{y}$, los intereses que se hubieran devengado. b) la modalidad de jubilación que se adopte el trabajador, es decir: retiro programado, renta vitalicia personal, renta vitalicia familiar; y/o renta temporal con renta vitalicia diferida.

(vii)El SNP otorga a favor del trabajador las siguientes prestaciones: pensión de jubilación e invalidez; y, a favor de sus familiares sobrevivientes; pensión de viudez, orfandad, ascendencia y capital de defunción. En cambio, las prestaciones que ofrece el SPP son las siguientes: pensión de jubilación e invalidez sobrevivencia y gastos por sepelio. En este sistema no se otorgan prestaciones en materia de salud y de accidentes de trabajo.

(viii) En el SPP, a diferencia del SNP, la legislación ha dispuesto la posibilidad de que los empleadores realicen aportes voluntarios a la cuenta individual de los

\footnotetext{
${ }^{11}$ Artículo 4 del Decreto Supremo No 054-97-EF, Texto Único Ordenado de la Ley del Sistema Privado de Administración de Fondos de Pensiones.

${ }^{12}$ TOYAMA MIYAGUSUKU, Jorge y ÁNGELES LLERENA, Karen. (2004) Óp. Cit.

${ }^{13}$ Ibídem.

e-Revista Internacional de la Protección Social, ISNN 2445-3269. 2018, Vol. III, Nº 1

http://dx.doi.org/10.12795/e-RIPS.2018.i02.07. Páginas: 135-149.

Página 141
} 
trabajadores con fin provisional, sin que exista algún límite cuantitativo al respecto.

En suma, de acuerdo al ordenamiento previsional vigente, el Estado peruano ha instaurado la coexistencia de dos sistemas de pensiones que son excluyentes entre sí, otorgándose a los trabajadores la libertad de optar por afiliarse voluntariamente a alguno de ellos.

Adicionalmente a los regímenes expuestos anteriormente, el Sistema Previsional en el Perú está conformado por el Sistema de Cédula Viva, regulado por el Decreto Ley $\mathrm{N}^{\mathrm{o}}$ 20530. El régimen tuvo su origen en leyes antiguas que concedían pensiones vitalicias para un grupo reducido de funcionarios del Estado y a cargo del Tesoro Público ${ }^{14}$.

En este régimen están comprendidos los trabajadores públicos, fiscales (Decreto Legislativo $N^{\circ}$ 052), magistrados (Decreto Supremo $N^{0}$ 017-93-JUS), diplomáticos (Decreto Legislativo No 894), JNE, Tribunal Constitucional, trabajadores del Banco de la Nación (Decreto Legislativo No 339), EsSalud (Leyes No 25066 y No 24366). Asimismo, no se establece una edad mínima para gozar de la pensión de jubilación. Sólo se requiere 12.5 años (mujeres), 15 años (hombres) y 20 años.

\section{LA NECESIDAD DE LA REFORMA: PROBLEMÁTICA CON EL SISTEMA DE PENSIONES}

El Sistema Previsional en el Perú ha sufrido constantes modificaciones legislativas. Precisamente, la modificación más polémica durante los últimos años ha sido la promulgación en el 2016 de la Ley No 30425, norma que modificó el Decreto Supremo No 053-97-EF, que aprobó el Texto Único Ordenado de la Ley (TUO) del SPP.

En efecto, mediante la incorporación de la Vigésimo Cuarta Disposición Final y Transitoria, se dispuso que los afiliados de las AFP, a partir de los 65 años de edad, podrán decidir entre percibir la pensión que le corresponda en cualquier modalidad de retiro; o, solicitar a la AFP la entrega del 95.5\% del fondo disponible en su CIC.

De igual modo, otro los cambios relevantes que introdujo la Ley $\mathrm{N}^{\mathrm{o}} 30425$, fue la incorporación de un párrafo al artículo 40 al TUO de la Ley del SPP, según el cual los afiliados tienen la posibilidad de retirar hasta el $25 \%$ de la CIC y utilizar dicho monto como garantía de la cuota inicial de un crédito hipotecario destinado para la adquisición de una primera vivienda. Inclusive, dicha opción puede ejercerse en cualquier etapa de la afiliación.

Asimismo, se añadió el artículo 42-A al TUO de la Ley del SPP, a fin de establecer que procede también la jubilación anticipada cuando el afiliado padezca de enfermedad terminal o diagnóstico de cáncer que reduzca su expectativa de vida, debidamente declarada por el comité médico evaluador calificado por la SBS.

${ }^{14}$ CASALÍ, Pablo y PENA, Hernán. Los trabajadores independientes y la Seguridad Social en el Perú.

e-Revista Internacional de la Protección Social, ISNN 2445-3269. 2018, Vol. III, No 1

http://dx.doi.org/10.12795/e-RIPS.2018.i02.07. Páginas: 135-149.

Página 142 
Sin duda, esta norma ha sido objeto de serios cuestionamientos, ya que se ha señalado que estamos frente a una norma inconstitucional, en tanto transgrede el principio constitucional de la intangibilidad de los fondos de pensiones recogido en el artículo $12^{\circ}$ de la Constitución, el mismo que tiene la finalidad de salvaguardar los intereses de todos aquellos afiliados a un fondo de pensiones, ya sea público o privado, y que nunca se destinen dichos fondos a fines distintos de aquellos para los que fueron creados ${ }^{15}$.

Si bien entendemos que la finalidad de la norma era generar una mayor liquidez para los afiliados a los sistemas de pensiones; no obstante, la disponibilidad del fondo de pensión atenta con la misma naturaleza de la pensión, pudiendo generar que la población al llegar a la edad de jubilación no cuenten con fondos para garantizar una vejez digna. Ahora bien, recordemos que la reforma del Sistema de Pensiones peruano de 1992, tuvo como principal objetivo proveer de la sostenibilidad financiera que este sistema no tenía. De esta manera, el cierre de la brecha fiscal era fundamental para la estabilidad macroeconómica y se consideraba que la incorporación de un componente privado en la gestión del sistema de pensiones sería capaz de incentivar el ahorro en el país, canalizar recursos financieros a personas y empresas e impulsar el desarrollo del mercado de capitales y el crecimiento económico ${ }^{16}$.

En efecto, después de más de 20 años de la reforma, examinaremos brevemente las estadísticas elaboradas por la SBS más recientes ${ }^{17}$, a fin de verificar la implementación de la sostenibilidad financiera del SPP que se buscó con dicha reforma:

- En relación al número de afiliados, tenemos que las personas que se afiliaron al SPP durante el cuarto trimestre del año 2017 sumaron 97 004, cifra similar a la registrada en el trimestre anterior pero mayor en $10,9 \%$ con respecto al flujo registrado en el cuarto trimestre de 2016 (87 457 afiliaciones).

\section{Afiliación Trimestral por Tipo de Trabajador (En miles de personas)}

- En cuanto a la recaudación de aportes, éste ascendió a 2675 millones de soles durante el cuarto trimestre del 2017, registrando así un aumento de 5,5\% en relación a la registrada en el trimestre anterior y un crecimiento de $11,3 \%$ con respecto a la recaudación del cuarto trimestre del 2016 (2 403 millones de soles).

\footnotetext{
${ }^{15}$ COMISIÓN DE INVESTIGACIÓN DEL EQUIPO DE DERECHO MERCANTIL. “¿Es constitucional que un afiliado al sistema privado de pensiones pueda acceder hasta el $95.5 \%$ de los fondos de su cuenta individual de capitalización?". (2017) En: Revista de Actualidad Mercantil, No 5. VILLARÁN ZEGARRA, José Alberto. "Y ahora, ¿Quiénpodrá defendernos (de los riesgos)? Análisis de la Vigésima Cuarta Disposición Final de la ley $\mathrm{N}^{\circ} 30425$ que aprueba el retiro de $95.5 \%$ del Fondo Privado de Pensiones". (2016) Artículo Académico publicado como parte del Programa de Segunda Especialidad en Derecho del Trabajo y Seguridad Social de la Pontificia Universidad Católica del Perú.

16 TUESTA, David (2011), "Una revisión de los sistemas de pensiones en latinoamérica", BBVA Research.

${ }^{17}$ Informe de Evolución del Sistema Privado de Pensiones al Cuatro Trimestre de 2017. Disponible en: http://www.sbs.gob.pe/app/stats/EstadisticaBoletinEstadistico.asp?p=34\#.

e-Revista Internacional de la Protección Social, ISNN 2445-3269. 2018, Vol. III, Nº 1

http://dx.doi.org/10.12795/e-RIPS.2018.i02.07. Páginas: 135-149.

Página 143
} 
- Respecto a las solicitudes de traspaso aceptadas en el cuarto trimestre del año, éstassumaron13 862, flujo mayor en $13,6 \%$ al registrado en el trimestre previo pero menor en 5,4\% con relación a diciembre de 2016. Sin embargo, en términos de montos netos (ingresos menos salidas), solo una de las cuatro administradoras del SPP registró un crecimiento de ingresos como resultado de la dinámica de traspasos.

- Por otro lado, en cuanto a la recaudación de aportes, éste ascendió a 2675 millones de soles durante el cuarto trimestre del 2017, registrando así un aumento de $5,5 \%$ en relación a la registrada en el trimestre anterior y un crecimiento de $11,3 \%$ con respecto a la recaudación del cuarto trimestre del 2016 (2 403 millones de soles).

Aportes al SPP

(En millones de soles)

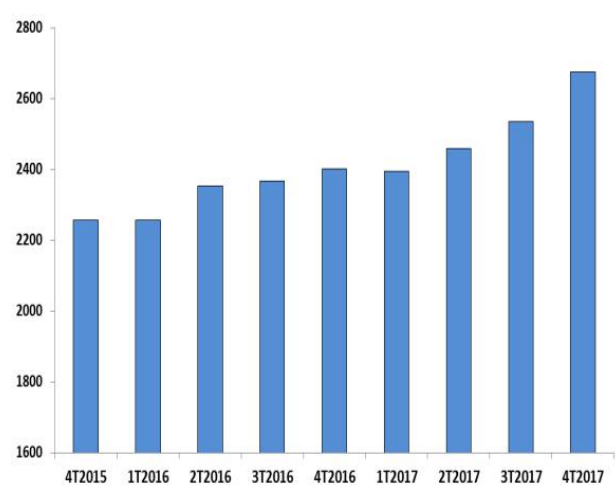

- Finalmente, en cuanto a las utilidades de las AFP, al cierre de diciembre de 2017, la utilidad operativa del SPP descendió a 610 millones de soles, monto inferior al registrado en diciembre del 2016 (631 millones de soles).

En efecto, de acuerdo con las estadísticas a las que hemos hecho referencia concordamos con quienes afirman que luego de más de 20 años de funcionamiento del SPP, de cierto modo, la reforma alcanzó alguno de sus objetivos financieros ${ }^{18}$. No obstante, las deficiencias del sistema se presentan en el plano social; ya que, por ejemplo, sólo la tercera parte de la fuerza laboral se encuentra afiliada al SPP, porcentaje que se reduce a menos de $20 \%$ si se consideran afiliados con aportes regulares. La alta informalidad, los serios problemas de liquidez que tiene este colectivo, así como la pobre cultura previsional de la población no han favorecido el incremento de la cobertura de manera significativa ${ }^{19}$.

\footnotetext{
${ }^{18}$ ALONSO, Javier; SÁNCHEZ, Rosario; y TUESTA, David. (2014). "Un modelo para el sistema de pensiones el Perú: Diagnóstico y recomendaciones". En: Revista de Estudios Económicos, No 27. Disponible en: http://www.bcrp.gob.pe/docs/Publicaciones/Revista-Estudios-Economicos/27/ree-27alonso-sanchez-tuesta.pdf.

${ }^{19}$ Ibídem.

e-Revista Internacional de la Protección Social, ISNN 2445-3269. 2018, Vol. III, No 1

http://dx.doi.org/10.12795/e-RIPS.2018.i02.07. Páginas: 135-149.

Página 144
} 
Asimismo, en un país emergente como el nuestro, existen un conjunto de limitaciones que restringen la función del Estado de garantizar una protección social mínima a la población, dentro de las cuales tenemos ${ }^{20}$ : escasos recursos fiscales, la elevada informalidad y baja productividad laboral; cambios en la composición demográfíca asociados al envejecimiento poblacional y el descenso de aportantes jóvenes y los bajos niveles de empleo.

En un estudio reciente elaborado por un grupo de especialistas contratados por el Estado peruano han llegado a la conclusión que existen una serie de problemas críticos que dificultan el correcto funcionamiento del Sistema Previsional en el Perú ${ }^{21}$, como por ejemplo:

1. Tenemos un modelo altamente fragmentado y carente de visión integral conformado por dos regímenes contributivos que compiten por la misma población objetivo (los trabajadores del sector formal) y un pilar no contributivo que actúa de manera aislada como un programa social (Pensión 65).

2. El nivel de cobertura es bajo y decreciente, producto de un sistema enfocado fundamentalmente en el mercado laboral formal (de trabajadores asalariados). En la actualidad, solo un $16.8 \%$ de la activa (PEA) aporta al sistema previsional y sólo el 35\% de los ciudadanos mayores de 65 años forma parte de algún sistema previsional.

3. Los sistemas ofrecen pensiones insuficientes e inequitativas. En la actualidad, sólo el $13.7 \%$ de la PEA peruana puede realistamente aspirar a recibir una pensión del SNP o SPP en la vejez, y la pensión promedio, para los pocos que la reciben, es baja comparada con las pensiones promedio en, digamos, Colombia, Chile y México. El sistema actual, además, alberga profundas inequidades. Por ejemplo, mientras que una persona que haya contribuido menos de 20 años al SNP termina sin pensión al jubilarse ni acceso a sus aportes, una persona de la misma edad y con similares niveles de ingreso y aportes al SPP podría adquirir una renta vitalicia razonable.

4. En el caso del SPP, el desaprovechamiento de economías de escala y el mercado oligopólico de AFP impide la reducción de costos y que ésta se traduzca fácilmente en menores comisiones para los afiliados, al tiempo que posibilita altas tasas de ganancia para las AFP.

5. Una gestión de portafolios cortoplacista por parte de las AFP. Dicha gestión es en general inconsistente con el objetivo de largo plazo del ahorro previsional.

\footnotetext{
${ }^{20}$ COMISIÓN DE PROTECCIÓN SOCIAL. "Propuestas de reformas en el Sistema de Pensiones, financiamiento en la Salud y Seguro de Desempleo". (2017). Disponible en: http://www.proteccionsocial.com.pe/assets/pdf/Informe_Final_CPS.pdf

${ }^{21}$ Ibídem.

e-Revista Internacional de la Protección Social, ISNN 2445-3269. 2018, Vol. III, No 1

http://dx.doi.org/10.12795/e-RIPS.2018.i02.07. Páginas: 135-149.

Página 145
} 
6. La existencia en el SPP de dificultades para acceder a esquemas de retiro simples que aseguren la estabilidad de los ingresos en la jubilación a costos razonables, frente a un incremento persistente en la esperanza de vida.

7. La ausencia de información y asesoría financiera adecuada, activa, independiente, simple y de fácil acceso para el afiliado, tal que le ayude a planificar y administrar mejor su ingreso en la fase de jubilación y le alerte de posibles malas decisiones en materia previsional.

Así, A lo anterior, se suma que, de acuerdo con el Ministerio de Economía y Finanzas peruano, el Sistema Público de Pensiones se encuentra desfinanciado y requiere transferencias del Tesoro Público que representan el 16\% del Presupuesto Público y el $30 \%$ de la recaudación interna de tributos. El Régimen del Decreto Ley N ${ }^{\circ} 20530$ es el que presenta las mayores distorsiones y representa la mayor carga previsional que afronta el Estado 22 .

En este marco, desde un punto de vista constitucional, el Estado tiene la obligación de velar por la seguridad social de los individuos; por lo que, en respuesta a los problemas existentes con el Sistema de Pensiones surge la necesidad de una reforma que se traduzca en la posibilidad de que la población pueda acceder a mejores pensiones y se diseñe un plan de retiro acorde a sus posibilidades y necesidades.

\section{REFORMA EN CAMINO: SISTEMA DE PENSIONES INTEGRADO}

Las graves deficiencias en el Sistema de Pensiones peruano son evidentes. De este modo, el Sistema de Pensiones ha vuelto a ser objeto de debate y se han puesto sobre la mesa distintas propuestas para impulsar una serie de reformas ${ }^{23}$, las cuales han sido propuestas tanto desde el frente de las AFP, como desde el Estado.

Al respecto, en enero del 2017 se emitió la Resolución Ministerial No 017-2017-EF/10, mediante la cual se creó el Grupo de Trabajo denominado "Comisión de Protección Social" (CPS), dependiente del Ministerio de Economía y Finanzas. Dicha Comisión se creó con el objeto de plantear reformas económicas para financiar la cobertura universal de aseguramiento de salud y protección previsional, además de mejorar la protección frente al desempleo; sin afectar la sostenibilidad fiscal ni generar informalidad en el mercado de trabajo.

En efecto, en septiembre del 2017 la CPS presentó su informe final denominado "Propuestas de Reformas en el Sistema de Pensiones, Financiamiento en la Salud y Seguro de Desempleo". En dicho informe, la CPS propuso su reforma integral del Sistema de Pensiones.

\footnotetext{
${ }^{22}$ DIRECCIÓN GENERAL DE ASUNTOS ECONÓMICOS Y SOCIALES DEL MINISTERIO DE ECONOMÍA Y FINANZAS. "Los Sistemas de Pensiones en el Perú" (2004). Disponible en: https://www.mef.gob.pe/contenidos/pol_econ/documentos/sistemas_pensiones.pdf

${ }^{23}$ Noticia extraída de: https://elcomercio.pe/economia/peru/son-propuestas-reforma-sistema-pensionesnoticia-466576

e-Revista Internacional de la Protección Social, ISNN 2445-3269. 2018, Vol. III, Nº 1

http://dx.doi.org/10.12795/e-RIPS.2018.i02.07. Páginas: 135-149.

Página 146
} 
Así, la CPS propone desarrollar un sistema de pensiones de afiliación automática, integrado, eficiente e independiente de la condición laboral, que fomente el ahorro con solidaridad para la vejez y que fortalezca y estabilice el ingreso en la etapa de jubilación sujeto a la disponibilidad de recursos fiscales, de modo que ningún peruano se quede sin una pensión básica ${ }^{24}$.

Los objetivos de la reforma propuesta son:

1. Construir un sistema de pensiones único e integrado.

2. Ampliar sustancialmente la cobertura del sistema pensional, principalmente a través de la introducción de una pensión básica (antipobreza).

3. Reducir los costos del sistema para el trabajador que ahorra para su vejez, a través de un mayor aprovechamiento de economías de escala en favor de los afiliados, una reducción de gastos innecesarios, una mejor y mayor diversificación de riesgos, y un despliegue más efectivo del papel rector del Estado en cuanto a la aglomeración eficiente de los servicios de administración de cuentas así como a la regulación y el ordenamiento de los mercados de servicios financieros relevantes (administración de activos, provisión de rentas vitalicias y seguros).

4. Incorporar un verdadero representante de la demanda (del colectivo de los afiliados).

5. Incrementar los beneficios del sistema pensional, no solo a través de la mencionada pensión básica, ampliación de la cobertura y reducción de comisiones, sino también a través de un nuevo marco regulatorio que focalice la atención de los trabajadores y gestores de activos en la tasa de reemplazo (esto es, en el ingreso durante la etapa de jubilación como porcentaje del ingreso en la etapa de trabajo).

En este sentido, el nuevo sistema pensional estaría conformado por tres pilares complementarios:

- $\quad$ Primer pilar: una pensión básica universal, en donde se apuntaría inicialmente a una pensión mínima de manera subsidiaria, esto es, mediante un subsidio público focalizado en los afiliados de menores ingresos. El subsidio decrecería con el nivel de ahorro previsional acumulado por la persona al momento de su jubilación de manera de no eliminar por completo los incentivos a ahorrar en las poblacionales de menores recursos.

- Segundo pilar: ahorro con verdaderos fines previsionales, esto es, enfocado en la tasa de reemplazo. Todos los ciudadanos en edad de trabajar (sean formales o informales) tendrían una CIC en la que se irían acumulando sus ahorros.

${ }^{24}$ DIRECCIÓN GENERAL DE ASUNTOS ECONÓMICOS Y SOCIALES DEL MINISTERIO DE ECONOMÍA Y FINANZAS. "Los Sistemas de Pensiones en el Perú" (2004). Óp. Cit.

e-Revista Internacional de la Protección Social, ISNN 2445-3269. 2018, Vol. III, No 1

http://dx.doi.org/10.12795/e-RIPS.2018.i02.07. Páginas: 135-149.

Página 147 
Asimismo, existiría una entidad centralizadora que capturaría economías de escala en favor del afiliado, eliminaría costos que no traen claros beneficios sociales, representaría el interés colectivo de los afiliados ante los gestores de carteras de inversión, y proveería (directamente o a través de terceros) adecuados servicios de información y asesoría financiera a los afiliados.

Este pilar contaría con un conjunto de incentivos estatales: (i) un subsidio a las contribuciones de los peruanos jóvenes de menores ingresos; (ii) un sistema de contribuciones complementarias (o aparejadas) por parte del Estado a los aportes de ahorro previsional hechos por trabajadores de menores ingresos; o, (iii) La facilitación de aportes de ahorro previsional a las CIC por vía de facturas de gasto (por ejemplo, facturas de pago por servicios de telefonía celular).

- Tercer pilar:desacumulación, que facilite la estabilidad de un ingreso decente durante el periodo de jubilación mediante el desarrollo de un mercado de rentas vitalicias simple, eficiente y barato junto con esquemas idóneos de retiro programado de los ahorros del trabajador.

Sin duda la propuesta expuesta responde a los problemas que viene afrontando el Sistema Previsional en el Perú. Inclusive, analistas y empresas del sector saludaron las propuestas. Por ejemplo, podemos a mencionar a el presidente ejecutivo de Sura -dueña de AFP Integra-, Jorge Ramos, quien consideró adecuado el planteamiento que ha hecho la CPS formada por el gobierno para que la ONP, las AFP y Pensión 65 se articulen en un sistema integral y dejen de competir por los afiliados ${ }^{25}$.

No obstante, también existe un sector que ha advertido riesgos en la reforma planteada por CPS. Así, la presidenta de la Asociación de AFP , Giovanna Prialé, señaló que "el esquema que propone esta comisión de centralizar la recaudación es un esquema de alto riesgo, porque no sabemos si este será de carácter público o privado, y eso, en un gobierno con fuerte apetito de gasto fiscal, puede traducirse en la nacionalización de los fondos de pensiones" 26 .

Naturalmente, los objetivos de la reforma propuesta se irían alcanzando en el tiempo, luego de una etapa de transición y conforme la reforma vaya estableciendo las necesarias condiciones de mercado y los arreglos institucionales adecuados. Para ello, se requiere que la implementación de la reforma vaya de la mano con la estrategia de política pública orientada a la formalización de la economía.

\footnotetext{
${ }^{25}$ Noticia extraída de: http://rpp.pe/economia/economia/como-deberia-ser-la-reforma-del-sistema-depensiones-noticia-1047209. Por su parte, el ex intendente de AFP de la Superintendencia de Banca y Seguros, Melvin Escudero, explicó cómo sería este pilar solidario.

"En el Perú, más o menos con ese espiritu, ya se implementó lo de Pensión 65, dentro de este modelo integrado nuevo debe de haber también ese pilar donde el Estado contribuye con una parte del financiamiento para la población más necesitada que sabemos que no va a alcanzar ese nivel de ahorro", refirió.

${ }^{26}$ Noticia extraída de: https://peru21.pe/economia/informe-21-alertan-riesgos-reforma-sistema-pensiones384273

e-Revista Internacional de la Protección Social, ISNN 2445-3269. 2018, Vol. III, No 1

http://dx.doi.org/10.12795/e-RIPS.2018.i02.07. Páginas: 135-149.

Página 148
} 


\section{REFLEXIÓN FINAL}

Si consideramos que actualmente la mayoría de la población en edad de jubilación ha optado o está considerado seriamente retirar el $95.5 \%$ de sus fondos del $\mathrm{SPP}^{27}$ para llevarlos a alguno de los planes de ahorro que ofrece el sistema financiero, negar el fracaso del sistema previsional actual y de la reforma de los años noventa sería claramente inconsecuente.

Por tanto, cae de madura la necesidad que existe en el Perú de una reforma. La pregunta en todo caso es ¿qué tipo de reforma?.

$\mathrm{Al}$ respecto, opinamos que cualquier cambio en el sistema de pensiones debe tener en cuenta un concepto básico, que aun cuando ha sido reiteradamente señalado por nuestro Tribunal Constitucional ${ }^{28}$, parece omitido por el legislador.

Dicho concepto no es otro que el recordar que la función social del Estado, es la de ser el garante primario y último del derecho de la Seguridad Social y, por tanto, del derecho fundamental de la pensión.

En tal sentido, el Estado se ve en la obligación de asumir y ejecutar medidas eficaces y constantes para alcanzar progresivamente la efectividad del sistema.Por tanto, el Estado requiere implementar un modelo de organización sostenible, regido por los principios de progresividad, universalidad y solidaridad, que permita garantizar pensiones dignas, adecuadas y eficientes ${ }^{29}$.

En nuestra opinión, dicho modelo, hacia el cual además parece orientarse la reforma peruana, según hemos señalado de manera precedente, es el modelo multipilar, mixto o complementario; donde se combina una pensión mínima digna (universal y solidaria), con una cuenta individual que le permitirá tener una mejor tasa de reemplazo a los trabajadores de ingresos medios y altos.

Así, nos parce que la necesidad de una reforma en el sistema de pensiones en el Perú es inminente, sólo esperamos que el resultado de la misma se oriente por los principios de la seguridad social y que no se sumerja nuevamente en los encantos irreales del interés individual o peor aún, el de algunos particulares.

\footnotetext{
${ }^{27}$ Conforme a lo dispuesto en la Ley $\mathrm{N}^{\mathrm{o}} 30425$ antes mencionada.

${ }^{28}$ Por ejemplo en las sentencias recaídas en los expedientes $\mathrm{N}^{\circ} 008-2013-\mathrm{Al} / \mathrm{TC}, \mathrm{N}^{\circ} 050-2004-\mathrm{AI} / \mathrm{TC}, \mathrm{N}^{\circ}$ 1417-2005-AA/TC, entre otras.

${ }^{29}$ GONZALES, César y PAITÁN, Javier. "Hacia un modelo multipilar del sistema de pensiones peruano: ¿Una reforma impostergable?”. En: Revista Diálogo y Concertación Nacional del Consejo Nacional del Trabajo del Ministerio de Trabajo y Promoción del Empleo, Ministerio de Trabajo y Promoción del Empleo, Lima, 2015.

e-Revista Internacional de la Protección Social, ISNN 2445-3269. 2018, Vol. III, No 1

http://dx.doi.org/10.12795/e-RIPS.2018.i02.07. Páginas: 135-149.

Página 149
} 